\title{
CONSULTR DE nUTRICIÓn Una parte del quehacer diario.
}


s difícil definir nutrición si queremos incorporar todos los elementos que conlleva esta profesión.

Podemos decir que es la ciencia que estudia los alimentos y su relación con el ser humano. Sin dejar de lado todos los aspectos sociales, psicológicos, culturales, económicos que tienen relación directa con nuestra forma de alimentarnos.

La nutrición se requiere en condiciones de carencia de recursos como en condiciones de abundancia y es vital la participación del nutricionista en la prevención de la enfermedad y para la promoción de la salud.

Cuando trabajamos en comunidad es difícil olvidar las atenciones de la gente y el arraigo que hay en nuestro país por el ofrecer un "bocadito "o un "gallito "al visitante, dejando latente que mostramos amor por medio de la alimentación.

De ahí que en ocasiones nuestra labor de fomentar buenos hábitos de alimentación se vea obstaculizada por ese afán de las abuelitas de ver cachetones a sus nietos, con la falsa idea que el niño gordito es el niño saludable. O de darle caldo de frijol con guineo, para quitarles la anemia.

A nivel hospitalario el nutricionista está enfocado en varios aspectos, pero hay que destacar el trabajo con profesionales de otras áreas de la salud, para lograr una atención integral del ser humano. Si todos dejáramos de lado nuestros egos, esa tarea no sería tan difícil.

Recorrer los pasillos del hospital, anotando las necesidades de un paciente y de otro, haciendo conts de ingesta, lidiar día a día en el servicio de alimentación para mantener la calidad y la inocuidad de la comida, son solo algunos de los aspectos que debemos vigilar.
El papel del nutricionista también está en la industria de alimentos, en la promoción y mercadeo de productos, investigación y otras áreas. Muchos colegas hacen un trabajo innovador en aspectos que no son tan reconocidas, pero ahí seguimos... porque insisto, la nutrición es parte de nuestra vida.

La consulta privada es un mundo diferente, se propicia el espacio para conversar, para escuchar... tenemos la oportunidad de establecer un vínculo con quien tenemos al frente. Nuestra participación puede ser menos activa, cuando quien nos visita no deja de conversar sobre su vida y su estilo de alimentación.

Nuestra labor es guiar, orientar y gracias a Dios cada vez más colegas reconocen que no debemos regañar ni imponer nuestros criterios, es mejor y más provechoso negociar para lograr el cambio de hábitos de alimentación.

La apertura de nuestro consultorio de nutrición es una gran alegría... podemos desarrollar nuestra labor y propiciar cambios alimentarios que darán salud a nuestra comunidad. Poco a poco podremos integrar a nuestros estudiantes de nutrición, para que desarrollen más destrezas para cumplir con nuestro propósito: trabajar con el alimento y su relación con el ser humano, en la búsqueda de un estilo de vida más saludable para todos.

En la Escuela de Nutrición de UCIMED tenemos muchos motivos para estar felices con nuestro consultorio, porque desde esa trinchera seguiremos trabajando en la formación de profesionales éticos, comprometidos y actualizados y además contribuir con la salud de nuestra comunidad. 